\section{OPEN ACCESS}

Edited by:

Miguel-Angel Gomez-Ruano,

Polytechnic University of

Madrid, Spain

Reviewed by:

Corrado Lupo,

University of Turin, Italy

Sadegh Amani-Shalamzari,

Kharazmi University, Iran

${ }^{*}$ Correspondence:

Julio Wilson Dos-Santos

julio.santos@unesp.br

Specialty section:

This article was submitted to

Movement Science and Sport

Psychology,

a section of the journal

Frontiers in Psychology

Received: 21 April 2021

Accepted: 21 June 2021

Published: 11 August 2021

Citation:

Silva HS, Nakamura FY, Papoti M, da

Silva AS and Dos-Santos JW (2021)

Relationship Between Heart Rate,

Oxygen Consumption, and Energy

Expenditure in Futsal.

Front. Psychol. 12:698622.

doi: 10.3389/fpsyg.2021.698622

\title{
Relationship Between Heart Rate, Oxygen Consumption, and Energy Expenditure in Futsal
}

\begin{abstract}
Henrique Santos da Silva ${ }^{1,2}$, Fabio Yuzo Nakamura ${ }^{3}$, Marcelo Papoti ${ }^{4}$, Alexsandro Santos da Silva ${ }^{1,2}$ and Julio Wilson Dos-Santos ${ }^{1,5 *}$

${ }^{1}$ Research Group on Exercise Physiology Applied to Sports Training (FITES), School of Science, São Paulo State University (UNESP), Bauru, Brazil, ${ }^{2}$ Post-Graduate Program in Motricity Sciences, São Paulo State University (UNESP), Bauru, Brazil, ${ }^{3}$ Research Center in Sports Sciences, Health Sciences and Human Development, CIDESD, University Institute of Maia, ISMAl, Maia, Portugal, ${ }^{4}$ School of Physical Education and Sport of Ribeirão Preto, University of São Paulo, Ribeirão Preto, Brazil, ${ }^{5}$ School of Science, Department of Physical Education, São Paulo State University (UNESP), Bauru, Brazil
\end{abstract}

The primary aim of this study was to compare the measured oxygen consumption (Measured- $\mathrm{VO}_{2}$ ) in a simulated futsal game (S-Game) with the estimated oxygen consumption (Estimated- $\mathrm{VO}_{2}$ ) through a regression equation between heart rate (HR) and oxygen consumption $\left(\mathrm{VO}_{2}\right)\left(\mathrm{HR}-\mathrm{VO}_{2}\right)$ in treadmill running, and a secondary aim was to calculate the total energy expenditure $(E E)$ in S-Game. Ten professional players (22.20 \pm 3.22 years) were evaluated. $\mathrm{HR}-\mathrm{VO}_{2}$ was determined individually in the

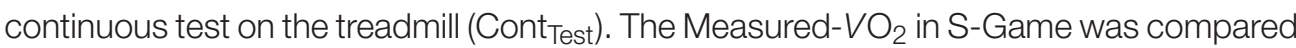

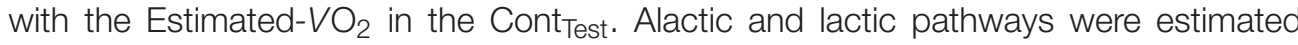
by $V_{2}$. The Estimated $-\mathrm{VO}_{2}$ presented no statistically significant difference with the Measured- $-\mathrm{VO}_{2}$, using the paired $t$-test $(p=0.38)$. However, the correlation between Estimated- and Measured- $\mathrm{VO}_{2}$ was very weak $(r=-0.05)$, and it presented poor agreement (concordance correlation coefficient $=-0.04$ ). In addition, a Bland-Altman plot presented bias of $-2.8 \mathrm{ml} / \mathrm{kg} / \mathrm{min}$ and individual difference as large as $19 \mathrm{ml} / \mathrm{kg} / \mathrm{min}$.

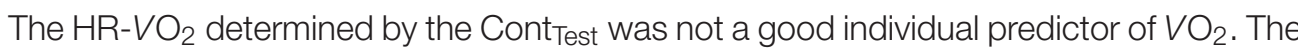
high intensity and intermittent nature of the futsal game possibly caused dissociation in the HR- $\mathrm{VO}_{2}$ relationship. Cont calculating individual EE in the futsal game. This is recommended only for the group mean. The total EE in S-Game was $13.10 \pm 1.25 \mathrm{kcal} \mathrm{min}^{-1}$ (10.81 \pm 1.57 metabolic equivalents). The contributions from the metabolic pathways were as follows: aerobic (93\%), alactic (5\%), and lactic (2\%).

Keywords: energy cost, metabolic equivalent, metabolic pathway, team sport, futsal match

\section{INTRODUCTION}

The linearity of the relationship between heart rate (HR) and oxygen consumption $\left(\mathrm{VO}_{2}\right)$ (HR- $\mathrm{VO}_{2}$ ) is observed in progressive continuous exercise (Achten and Jeukendrup, 2003). From the regression equation obtained in treadmill running, it is possible to estimate $V \mathrm{O}_{2}$ in team sports (Esposito et al., 2004; Castagna et al., 2007) and, consequently, the energy expenditure (EE) (Rodrigues et al., 2011; Makaje et al., 2012; Beato et al., 2016). 
However, the thermal and emotional stress and the dehydration of the competition can elevate the $\mathrm{HR}$ without affecting the $V \mathrm{O}_{2}$, changing the linearity of the $\mathrm{HR}-\mathrm{VO}_{2}$ (Esposito et al., 2004; Bangsbo et al., 2006), and inducing an estimation error (Achten and Jeukendrup, 2003; Buchheit et al., 2009). Despite that, $\mathrm{HR}-V \mathrm{O}_{2}$ has been accepted and proposed to estimate $V \mathrm{O}_{2}$ in intermittent sports, such as soccer (Esposito et al., 2004) and futsal (Castagna et al., 2007). However, Buchheit et al. (2009) do not recommend the use of $\mathrm{HR}-V \mathrm{O}_{2}$ to estimate $V \mathrm{O}_{2}$ in the handball game, since the estimated $V \mathrm{O}_{2}$ was lower than the $V \mathrm{O}_{2}$ measured in the game.

Concerning futsal, a team sport characterized by the intermittent actions of high intensity, accelerations, decelerations, and changes of direction (Makaje et al., 2012), the average intensity of game resulting in $90 \%$ maximum $\mathrm{HR}$ (Castagna et al., 2009), and blood lactate $\left(\left[\mathrm{La}^{-}\right]\right.$) can reach 8.3 $\mathrm{mmol} / \mathrm{L}$ (Dos-Santos et al., 2020), the HR- $V \mathrm{O}_{2}$ to predict gamespecific $V \mathrm{O}_{2}$ is still not clear. In addition, $\mathrm{HR}-V \mathrm{O}_{2}$ estimates only EE from the aerobic pathway, without considering the lactic and alactic anaerobic pathways. The contribution of the alactic anaerobic pathway from adenosine triphosphate-creatine phosphate (ATP-CP) can be made by calculating the fast component of excess postexercise oxygen consumption (EPOC) (Margaria et al., 1933; Beneke et al., 2002; Bertuzzi et al., 2007), while the EE of the lactic anaerobic pathway can be estimated through the $\mathrm{O}_{2}$ equivalent for [ $\mathrm{La}^{-}$] (Di Prampero and Ferretti, 1999). These two procedures have been adopted to estimate $\mathrm{EE}$ from the anaerobic pathways and to calculate total EE in different sports, such as in tae kwon do, climbing, rowing, and table tennis (Bertuzzi et al., 2007; de Campos Mello et al., 2009; Campos et al., 2012; Zagatto et al., 2016). However, EE from the aerobic pathway has not yet been used in the futsal game.

To our knowledge, there are as yet no studies investigating total EE in futsal, considering the three energetic pathways. Knowing the total EE allows better planning of diet and training. Thus, the primary objective of this study was to compare measured oxygen consumption (Measured- $\mathrm{VO}_{2}$ ) in a simulated futsal game (S-Game) with the estimated oxygen consumption (Estimated- $\mathrm{VO}_{2}$ ) through a regression equation between $\mathrm{HR}$ and $V \mathrm{O}_{2}$ obtained in the continuous test on the treadmill (Cont $\mathrm{Test}_{\mathrm{t}}$ ), and the secondary objective was to determine the total EE in SGame. Considering the intermittent characteristic and the high intensity of the futsal game, it is expected that the $\mathrm{VO}_{2}$ estimated through the regression equation between $\mathrm{HR}$ and $V \mathrm{O}_{2}$ in the continuous test does not present good agreement with the $\mathrm{VO}_{2}$ measured in the game. We hypothesized that the Estimated- $V \mathrm{O}_{2}$ would not correspond to the Measured- $\mathrm{VO}_{2}$ in S-Game.

\section{MATERIALS AND METHODS}

\section{Subjects}

Ten professional futsal players of a team participated in the study $(22.2 \pm 3.2$ years; $178 \pm 6 \mathrm{~cm} ; 70.2 \pm 9.7 \mathrm{~kg}$ and $11.8 \pm 4.5 \%$ of fat), all of them with a minimum experience of 5 years in futsal training and competition, i.e., daily training in two periods (3-4 h/day), 5-6 days/week. Players belonged to a team that played in the main competition in the State of São Paulo, Brazil, the Paulista League. Participants were previously informed of all procedures and signed a consent form. The design and protocol of the study conformed to the ethical standards established in the Declaration of Helsinki (2013) and was approved by the Ethics Committee of the University, according to the national laws (CAAE: 41515915.5.0000.5398).

\section{Proceedings}

The characteristics of the subjects were made by measuring height [using stadiometer (Welmy, Santa Bárbara do Oeste, Sã̃o Paulo, Brazil)], mass, and body composition [using the dualenergy X-ray absorptiometry (DXA), Discovery Wi, Hologic, Bedford, MA, USA], adopting all the procedures of the manufacturer. A Cont ${ }_{\text {Test }}$ was performed to obtain a linear regression equation $(y=a x+b)$ and to calculate the Estimated$V \mathrm{O}_{2}$ in S-Game. In addition, HR- $V \mathrm{O}_{2}$ was determined for each player in S-Game to analyze the slope of the linear equation and to compare it with that generated by Cont $\mathrm{Test}_{\text {. The }}$ Estimated- $V \mathrm{O}_{2}$ was compared with the Measured- $V \mathrm{O}_{2}$. The EE corresponding to each metabolic pathway (i.e., aerobic, alactic, and lactic anaerobic) was determined in S-Game. All tests were performed in random order between 9:00 a.m. and 12:00 p.m., without any vigorous physical exertion in the previous $24 \mathrm{~h}$. At least a 48-h interval was interspersed in the Cont ${ }_{\text {Test }}$ and S-Game for each player. The ambient temperature in all assessments varied between 28 and $32^{\circ} \mathrm{C}$.

\section{Continuous Test on the Treadmill (Cont Test $_{\text {) }}$ and Simulated Futsal Game (S-Game)}

The Cont Test $_{\text {was }}$ performed on a treadmill (Inbramed ATL, Porto Alegre, Brazil) with a slope of $1 \%$, an initial velocity of $8.0 \mathrm{~km} / \mathrm{h}$, and an increase of $1.0 \mathrm{~km} / \mathrm{h}$ at each minute, until exhaustion (Kuipers et al., 2003). The $V \mathrm{O}_{2 \max }$ was determined according to the criteria proposed by Howley et al. (1995). Players from the same team participated in the S-Game, which consisted of four outfield players and the goalkeeper, randomly selected, following the rules of futsal on the court measuring $40 \times 20 \mathrm{~m}$. The data collection time for each player in S-Game was $10 \mathrm{~min}$, since substitutions in futsal are unlimited, and in official matches, the players stay an average of $10 \mathrm{~min}$ playing effectively on the court before being substituted (Castagna et al., 2009; Makaje et al., 2012). In addition, a 10-min effort period has been used in the studies with S-Game (Castagna et al., 2009; Milioni et al., 2016). Considering the time taken for the data collection, the use of a portable gas analyzer, and the availability of players by the technical committee of the team, the data collection of SGame was performed with one player in each 10-min S-Game, on separated days by more than $48 \mathrm{~h}$. The physical coach of the team refereed the games, and the head coach was present to guide and encourage the players. Before the S-Game, a blood sample (i.e., $25 \mu \mathrm{l}$ of the earlobe) was taken from the players for the analysis of $\left[\mathrm{La}^{-}\right]$at rest, and after blood collection, $V \mathrm{O}_{2}$ was measured at rest for $10 \mathrm{~min}$ in a sitting position. Subsequently, the players performed a standardized 10-min warm-up (e.g., jogging-running free $=2 \mathrm{~min}$, dynamic exercises $=3 \mathrm{~min}$, and exercises with ball $=5 \mathrm{~min}$ ), and during the 10 - $\mathrm{min} \mathrm{S}$-Game, the $V \mathrm{O}_{2}$ and $\mathrm{HR}$ were also measured. After the S-Game, $V \mathrm{O}_{2}$ was 
TABLE 1 | Comparison between the measured oxygen consumption (Measured- $\mathrm{VO}_{2}$ ) in simulated futsal game (S-Game) and the estimated oxygen consumption (Estimated- $\mathrm{VO}_{2}$ ) estimated by the $\mathrm{HR}-\mathrm{VO}_{2}$ regression equation from the continuous treadmill test.

\begin{tabular}{|c|c|c|c|c|c|c|}
\hline & $\begin{array}{c}\text { Measured- } \mathrm{VO}_{2} \\
(95 \% \mathrm{Cl})\end{array}$ & $\begin{array}{c}\text { Estimated- } \mathrm{VO}_{2} \\
(95 \% \mathrm{Cl})\end{array}$ & $p$-value & $\begin{array}{c}\text { Cohen's ES } \\
\text { (d) }\end{array}$ & $\begin{array}{c}\text { Pearson's } \\
(r)\end{array}$ & $\begin{array}{l}\text { Lin's } \\
\text { (CCC) }\end{array}$ \\
\hline $\mathrm{VO}_{2}(\mathrm{~mL} \cdot \mathrm{Kg} \cdot \mathrm{min}-1)$ & $35.21 \pm 4.90(32.71-38.72)$ & $38.04 \pm 8.13(32.23-43.86)$ & 0.38 & 0.43 (small) & -0.05 (very weak) & -0.04 (poor) \\
\hline
\end{tabular}

Values expressed as mean $\pm S D$. HR, Heart rate; $V_{2}$, oxygen consumption; $E S$, effect size; $95 \% \mathrm{Cl}$ lower and upper limits.

measured at rest during $10 \mathrm{~min}$ for the EPOC examination, and the blood samples were taken at 1, 3, 5, and 7 min to determine $\left[\mathrm{La}^{-}\right]$peak.

\section{Measurements of the Physiological Parameters}

In all procedures, the HR was recorded for each second. The maximum $\mathrm{HR}\left(\mathrm{HR}_{\max }\right)$ was considered the highest value in

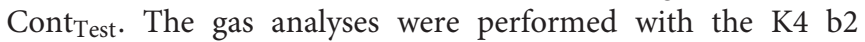
device (Cosmed Srl, Rome, Italy), with all calibrations and other procedures recommended by the manufacturer. The respiratory variables were smoothed every five points and interpolated every second to reduce the artifacts (Özyener et al., 2001). Estimated$V \mathrm{O}_{2}$ was calculated by $\mathrm{HR}-V \mathrm{O}_{2}$ for each player in Cont ${ }_{\mathrm{Tes}}$, obtaining a linear regression equation $(y=a x+b)$, and considering the mean of $\mathrm{HR}\left(\mathrm{HR}_{\text {mean }}\right)$ obtained in S-Game. Measured- $V \mathrm{O}_{2}$ was calculated by the area of $V \mathrm{O}_{2}$ by each $\mathrm{HR}$ record, disregarding the $\mathrm{VO}_{2}$ at rest, to determine EE only during futsal game.

Samples of $\left[\mathrm{La}^{-}\right]$were collected in capillary tubes (i.e., 50 $\mu \mathrm{l}$ of $1 \%$ sodium fluoride) and analyzed on YSI 2300 SPORTS (Yellow Springs Instruments, Yellow Springs, OH, USA). The energy demand of the aerobic $\left(W_{\mathrm{AER}}\right)$, alactic anaerobic $\left(W_{\mathrm{PCR}}\right)$, and lactic anaerobic $\left(W_{\left[\mathrm{La}^{-}\right]}\right)$metabolism was estimated as follows: $W_{\mathrm{AER}}=$ difference between the area of $V \mathrm{O}_{2}$ during the S-Game (i.e., calculated by the trapezoidal integration method) of the $V_{2}$ at rest (i.e., calculated by the product between the $\mathrm{VO}_{2}$ at rest and the total duration of the game) (Beneke et al., 2002; Bertuzzi et al., 2007; Campos et al., 2012); $W_{\text {PCR }}=$ fast component of EPOC measured after S-Game, i.e., calculated by the product between the amplitude and tau $(\tau)$ obtained by means of the bi-exponential adjustment of $\mathrm{VO}_{2}$ (Beneke et al., 2002; Bertuzzi et al., 2010); and $W_{\mathrm{Ca}^{-}}$ ] = difference between the peak lactate of the S-Game and at rest $\left(\Delta\left[\mathrm{La}^{-}\right]\right)$, considering the equivalent energy of $3 \mathrm{ml}$ of $\mathrm{O}_{2}$.per $\mathrm{kg}$ for each $1 \mathrm{mmol} / \mathrm{L}$ of $\left[\mathrm{La}^{-}\right.$] (Di Prampero and Ferretti, 1999). Thus, the total EE (i.e., $W_{\mathrm{AER}}+W_{\mathrm{PCR}}+W_{\mathrm{Ca}^{-}}$ ]) was expressed in several ways to facilitate its application, considering the equivalent for $\mathrm{O}_{2} \mathrm{ml} / \mathrm{kg} / \mathrm{min}$ in kilocalories (kcal) and metabolic equivalent (MET) (Bertuzzi et al., 2007; McArdle et al., 2014).

\section{Statistical Analysis}

The Shapiro-Wilk test was used to verify the normality of the data. After confirming the normality of the data, the paired $t$-test was applied. The 95\% CI was determined, and the effect size (ES) was calculated by using Cohen's $d$ (Cohen, 1988), considering
ES: $<0.19$ trivial, 0.20-0.49 small, 0.50-0.79 moderate, and $>0.80$ large. The Pearson's correlation was determined and classified according to the values of $r$ as follows: very weak (0.0-0.2), weak (0.2-0.4), moderate (0.4-0.7), strong (0.7-0.9), and very strong (0.9-1.0) (Glickman and Rowntree, 1982). The Bland-Altman analysis was used to verify the agreement between Measured- $V \mathrm{O}_{2}$ and Estimated- $V \mathrm{O}_{2}$, as well as the Lin's concordance correlation coefficient (CCC), following the scale for strength of agreement: poor $(<0.90)$, moderate $(0.90-$ 0.95), substantial (0.95-0.99), and almost perfect $(>0.99)$ (Lin, 1989). The level of significance was set at $5 \%$. The calculations were performed using the following statistical programs: IBM SPSS Statistics software for Windows, version 22.0 (IBM Corp, Armonk, NY, USA), and MedCalc 9.2 (MedCalc Software bv, Ostend, Belgium).

\section{RESULTS}

The values of Measured- $V \mathrm{O}_{2}$ and Estimated- $V \mathrm{O}_{2}$ presented no significant difference (Table 1). Considering only the $W_{\mathrm{AER}}$, the EE also did not differ statistically (i.e., measured $=12.19 \pm$ 1.09 and estimated $=13.32 \pm 3.17$ ). However, the correlations demonstrated that Estimated- $\mathrm{VO}_{2}$ did not correspond to Measured- $\mathrm{VO}_{2}$ individually (Table 1). In the Bland-Altman analysis (Figure 1), it is possible to observe the data scatter and the low agreement between the Estimated- $V \mathrm{O}_{2}$ and Measured$V \mathrm{O}_{2}$, a bias of $-2.8 \mathrm{ml} / \mathrm{kg} / \mathrm{min}$, and the limits of agreement varying in $19 \mathrm{ml} / \mathrm{kg} / \mathrm{min}$. When comparing the slope averages of the linear regression equation generated by the $\mathrm{HR}-\mathrm{VO}_{2}$ in the Cont Test $_{\text {( }}(0.48 \pm 0.12)$ and S-Game $(0.28 \pm 0.21)$, significant differences were observed between the slopes $(p=0.007)$. The correlation coefficients of the HR- $V \mathrm{O}_{2}$ in Cont Test,$r=0.95$ \pm 0.03 , and in S-Game, $r=0.61 \pm 0.27$, presented significant difference $(p=0.003)$, and the explication coefficients were $r^{2}$ $=0.91 \pm 0.05$ and $r^{2}=0.44 \pm 0.29$, respectively. The HR$V \mathrm{O}_{2}$ of a player in the two situations (i.e., Cont $T_{\text {Test }}$ and SGame) allows visualizing these differences (Figure 2). The SGame presented a high-intensity level as expected for futsal as follows: $\mathrm{HR}_{\text {mean }}=163 \pm 7 \mathrm{bpm}$, corresponding to $\mathrm{HR}_{\max }=90$ $\pm 4 \%$. The $\mathrm{HR}_{\max }$ in S-Game was $188 \pm 11 \mathrm{bpm}$, whereas it was $182 \pm 7 \mathrm{bpm}$ in Cont ${ }_{\text {Test }}$. $\left[\mathrm{La}^{-}\right]$peak after S-Game was $3.57 \pm$ $1.34 \mathrm{mmol} / \mathrm{L}$.

Table 2 shows the total EE and the proportions of the contribution of each energy pathway in the S-Game, disregarding the resting values of each individual. The anaerobic EE represented $7 \%$ of the total contribution in S-Game. 


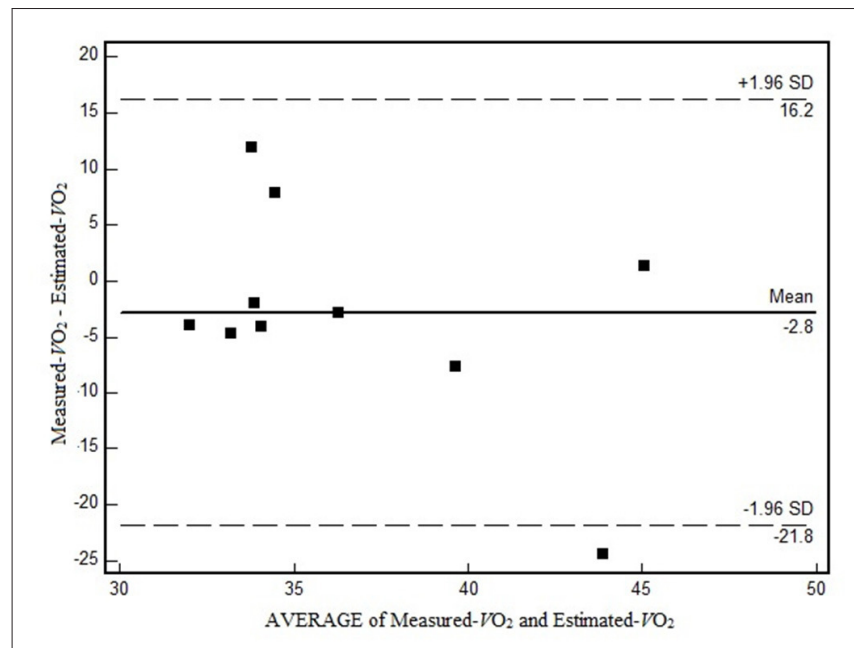

FIGURE 1 | The Bland-Altman analysis for oxygen consumption $\left(\mathrm{VO}_{2}\right.$ $\mathrm{ml} / \mathrm{kg} / \mathrm{min}$ ) between Measured- $\mathrm{VO}_{2}$ and Estimated $-\mathrm{VO}_{2}$.

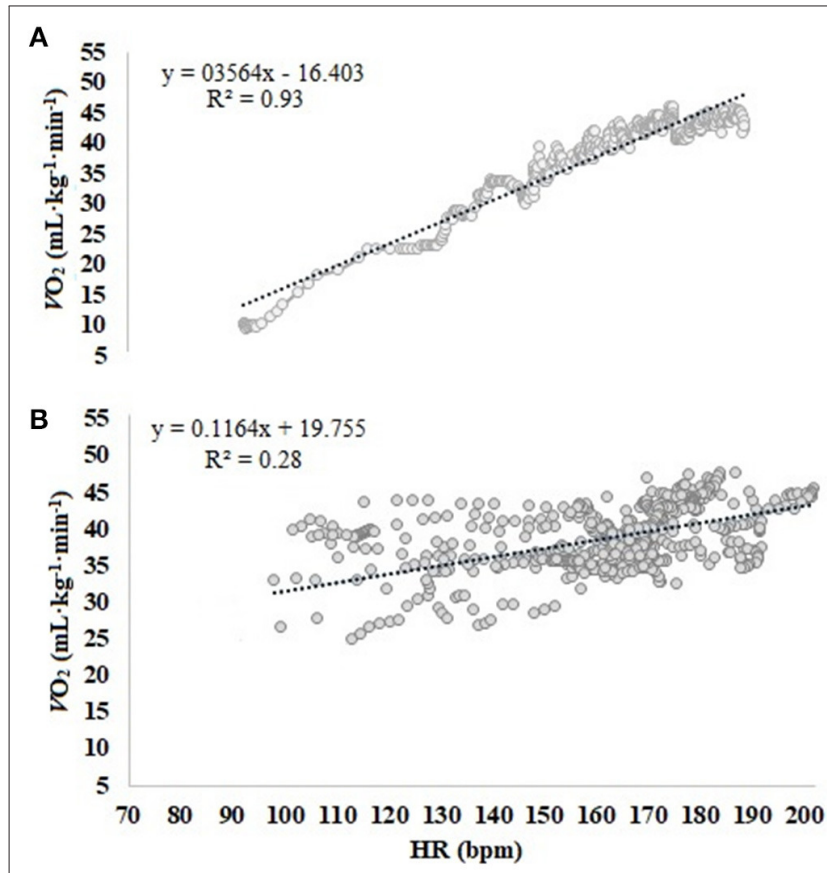

FIGURE 2 | Relationship between heart rate (HR, bpm) and oxygen consumption $\left(\mathrm{VO}_{2}, \mathrm{ml} / \mathrm{kg} / \mathrm{min}\right)$ of an athlete, during the tests: (A) continuous treadmill test (Cont Test ) and (B) simulated futsal game (S-Game).

\section{DISCUSSION}

The primary objective of this study was to compare the Measured- $V \mathrm{O}_{2}$ with the Estimated- $V \mathrm{O}_{2}$ in futsal, through the regression equations generated from the HR- $V \mathrm{O}_{2}$ obtained in the Cont ${ }_{T e s t}$. Although the Estimated- $V \mathrm{O}_{2}$ presented no significant difference with the Measured- $V \mathrm{O}_{2}$, they presented a very weak correlation and poor agreement (Table 1). It could
TABLE 2 | The energy expenditure of the aerobic $\left(W_{A E R}\right)$, alactic anaerobic $\left(W_{\mathrm{PCR}}\right)$, and lactic anaerobic $\left(W_{\left[\mathrm{La}^{-}\right]}\right)$metabolism in S-Game.

\begin{tabular}{lcccc}
\hline & $\boldsymbol{W}_{\text {AER }}$ & $\boldsymbol{W}_{\mathrm{PCR}}$ & $\boldsymbol{W}_{\text {[La-] }}$ & Total \\
\hline $\mathrm{VO}_{2}(\mathrm{ml} / \mathrm{kg} / \mathrm{min})$ & $35.21 \pm 4.90$ & $1.92 \pm 0.83$ & $0.70 \pm 0.39$ & $37.83 \pm 5.49$ \\
$\mathrm{VO}_{2}(\mathrm{~L} / \mathrm{min})$ & $2.44 \pm 0.22$ & $0.13 \pm 0.05$ & $0.05 \pm 0.03$ & $2.62 \pm 0.25$ \\
$\mathrm{EE}\left(\mathrm{kcal} . \mathrm{min}^{-1}\right)$ & $12.19 \pm 1.09$ & $0.66 \pm 0.25$ & $0.25 \pm 0.14$ & $13.10 \pm 1.25$ \\
$\mathrm{EE}(\mathrm{METs})$ & $10.06 \pm 1.40$ & $0.55 \pm 0.24$ & $0.20 \pm 0.11$ & $10.81 \pm 1.57$ \\
Percentage (\%) & $93.15 \pm 2.29$ & $4.99 \pm 1.70$ & $1.87 \pm 1.04$ & $100.00 \pm 0.00$
\end{tabular}

$V_{2}$, oxygen consumption; EE, energy expenditure; METs, metabolic equivalents.

be remarked that, according to this main finding, the HR$V \mathrm{O}_{2}$ determined by the Cont Test was not a good individual predictor of $\mathrm{VO}_{2}$. Considering the secondary objective, the aerobic energy demand in S-Game was $93 \%$, anaerobic alactic, $5 \%$, and anaerobic lactic, $2 \%$.

There was no significant difference (using the paired $t$ test) between the Measured- $V \mathrm{O}_{2}$ and the Estimated- $V \mathrm{O}_{2}$, indicating that our hypothesis should be refuted (i.e., HR$V \mathrm{O}_{2}$ of the Cont $T_{\text {Test }}$ would not be a good game-related $V \mathrm{O}_{2}$ predictor). However, the correlation and concordance tests evidenced the low predictive capacity of $V \mathrm{O}_{2}$ by $\mathrm{HR}-\mathrm{VO}_{2}$ from a test on the treadmill (i.e., Cont ${ }_{T e s t}$ ) for estimating $V \mathrm{O}_{2}$ in futsal game. In addition, the correlation coefficients from Cont Test $_{\text {and }} \mathrm{S}$-Game were different, $r=0.95$ and $r$ $=0.61$, respectively. In futsal recreational game with high school students, the estimated and measured $V_{2}$ in futsal game did not differ either (Castagna et al., 2007). Although the authors pointed out the validity of the estimation of $V \mathrm{O}_{2}$ from the regression equation in treadmill running, they stated that HR might have a less predictive capacity of real aerobic involvement during intermittent activities compared with continuous exercise. Therefore, they recommended that the HR- $\mathrm{VO}_{2}$ be only used for groups and not individually since the correlation coefficient of the $\mathrm{HR}-V \mathrm{O}_{2}$ presented a statistical difference $(p<0.001)$ between the futsal game $(r=0.83)$ and the treadmill running $(r=0.96)$. Those authors assumed that other occasional activities, such as high-speed running or isometric muscle actions, may explain some differences between $\mathrm{HR}$ and $V \mathrm{O}_{2}$ in intermittent exercise vs. continuous exercise. In addition, the heat and stress factors of the game can influence the dissociation of the response of $\mathrm{HR}-\mathrm{VO}_{2}$ (Achten and Jeukendrup, 2003). Another interesting result that must be taken into account when analyzing the $\mathrm{HR}-\mathrm{VO}_{2}$ is the intensity. Notably, in this study, the average $\mathrm{HR}$ was $\mathrm{HR}_{\max }=90 \%$, similar to the official games (Barbero-Alvarez et al., 2008), while in the recreational game with high school students, the average $\mathrm{HR}$ was $\mathrm{HR}_{\max }=$ 83\% (Castagna et al., 2007), resulting in a weaker correlation in the HR- $V \mathrm{O}_{2}$ when the game is more intense ( $r=0.61$ vs. 0.83 , respectively). However, the $\mathrm{HR}-V_{2}$ from the treadmill test has been used to estimate the $\mathrm{VO}_{2}$ in team sports, such as soccer.

In soccer, Hoff et al. (2002) indicated HR as a valid indicator of $\mathrm{VO}_{2}$ in a 5 vs. 5 small-sided game and in a dribbling field test. However, the authors used average values for the correlation analysis between $\mathrm{HR}$ and $\mathrm{VO}_{2}$ and did not compare the 
correlation coefficients between the different situations. Esposito et al. (2004) did not observe a significant difference between the $V \mathrm{O}_{2}$ measured in the specific field test to soccer and that estimated by the equation in the treadmill test, recommending that the $\mathrm{HR}-V \mathrm{O}_{2}$ regression equation obtained on the treadmill is valid to calculate $V \mathrm{O}_{2}$. In this study, Measured- $V \mathrm{O}_{2}$ and Estimated- $V \mathrm{O}_{2}$ by HR- $V \mathrm{O}_{2}$ were not different either. However, the results of the Estimated $-V \mathrm{O}_{2}$ by $\mathrm{HR}-V \mathrm{O}_{2}$ did not present concordance. We compared the Estimated- $V \mathrm{O}_{2}$ by $\mathrm{HR}-V \mathrm{O}_{2}$ with the Measured- $V \mathrm{O}_{2}$ in S-Game, which is more specific than a field test, as used in studies with soccer (Hoff et al., 2002; Esposito et al., 2004). Although in the study by Hoff et al. (2002), the subjects were also evaluated in a 5 vs. 5 small-sided soccer game, and the calculation of the individual $V \mathrm{O}_{2}$ using the HR- $V \mathrm{O}_{2}$ equation from the treadmill was not carried out (Hoff et al., 2002). Besides, futsal is more intense than soccer (Barbero-Alvarez et al., 2008), since the actions are carried out in a smaller space and with more frequent changes of direction. The intermittent characteristic and the high intensity of the futsal game certainly contributed to the difference observed between $\mathrm{HR}$ and $\mathrm{VO}_{2}$ of S-Game and one obtained in continuous exercise test (Figure 2). Considering different methods used in the studies, and although some authors recommended the use of the $\mathrm{HR}-V \mathrm{O}_{2}$ in soccer to estimate the $V \mathrm{O}_{2}$, the methods applied in this study demonstrated that the individual $\mathrm{HR}-\mathrm{VO}_{2}$ in continuous exercise in treadmill can estimate different $V \mathrm{O}_{2}$ values of the Measured- $V \mathrm{O}_{2}$ in futsal game for each player.

Contrary to the studies cited above, in a study with handball players, Buchheit et al. (2009) did not recommend the use of $\mathrm{HR}-V \mathrm{O}_{2}$ to estimate $V \mathrm{O}_{2}$. The authors found a good HR$\mathrm{VO}_{2}$ for the treadmill test of goodness of fit $\left(r^{2}=0.96\right)$ but a moderate $\mathrm{HR}-V \mathrm{O}_{2}$ for the handball game and intermittent exercise ( $r^{2}=0.63$ and $r^{2}=0.58$, respectively). Moreover, $V \mathrm{O}_{2}$ estimated from the $\mathrm{HR}-V \mathrm{O}_{2}$ in the treadmill test was lower than the $V \mathrm{O}_{2}$ measured in the handball game $(p=0.03)$. It was also possible to observe a large difference between $V \mathrm{O}_{2}$ measured in a handball game and that estimated from the intermittent exercise, 8.7 and $11.6 \mathrm{ml} / \mathrm{kg} / \mathrm{min}$, respectively. In handball, there are accelerations, decelerations, jumps, changes of direction, and actions of the upper limbs that increase the active muscle mass, which differs a lot from running on the treadmill.

The very weak correlation between Estimated- $V \mathrm{O}_{2}$ and Measured- $\mathrm{VO}_{2}(r=-0.05)$, ES estimated by Cohen's $d$, classified as small (0.4), and the CCC as poor (CCC $=-0.04)$ corroborate results observed in handball (Buchheit et al., 2009), making clear the difference between the characteristics of the continuous exercise with the intermittent sports. In our results (Figure 2), it is possible to observe the difference in the dispersion of the data between the two exercise situations evaluated. The difference found between the slopes of the regression lines, Cont $\mathrm{Test}_{\mathrm{T}}(0.48$ $\pm 0.12)$ and S-Game $(0.28 \pm 0.21)(p=0.007)$, is an indication that the $\mathrm{HR}-\mathrm{VO}_{2}$ responded differently in both Cont $\mathrm{Test}_{\text {and }}$ S-Game. A Bland-Altman plot in this study presented a bias of $-2.8 \mathrm{ml} / \mathrm{kg} / \mathrm{min}$ and individual difference as large as 19 $\mathrm{ml} / \mathrm{kg} / \mathrm{min}$. The result of bias was similar to those from another study on futsal, $-2.2 \mathrm{ml} / \mathrm{kg} / \mathrm{min}$, while the limit of agreement in this study was higher than $8 \mathrm{ml} / \mathrm{kg} / \mathrm{min}$ (Castagna et al., 2007), however, the higher limit of agreement, in comparison with the results of Castagna et al. (2007), $8 \mathrm{ml} / \mathrm{kg} / \mathrm{min}$. The higher intensity of the S-Game in this study $\left(90 \% \mathrm{HR}_{\max }\right)$ compared with $83 \% \mathrm{HR}_{\max }$ (Castagna et al., 2007) can explain the difference between the two studies. As a result, the higher the intensity of the intermittent exercise, the greater the dissociation in HR$V_{2}$, reinforcing the data from Balsom et al. (1992), which suggested that $\mathrm{HR}$ increased disproportionately to the $V \mathrm{O}_{2}$ after sprinting activities.

The low correlation and the agreement between Measured$V \mathrm{O}_{2}$ and Estimated- $V \mathrm{O}_{2}$ of this study indicate that the equations of $\mathrm{HR}-\mathrm{VO}_{2}$ generated from the continuous test are not good for estimating $V \mathrm{O}_{2}$ individually, and although there is no difference to estimate the "rough" $V \mathrm{O}_{2}$ of the group, it is not recommended to plan diets or the training load from this calculation, due to the biological individuality of each athlete and unpredictable situations in the game, which influence the $\mathrm{HR}-\mathrm{VO}_{2}$.

The use of $\mathrm{HR}-V \mathrm{O}_{2}$ in the estimation of $V \mathrm{O}_{2}$ in team sports should be viewed with caution since the literature presents contradictory results. Studies with soccer (Esposito et al., 2004) and futsal (Castagna et al., 2007) indicated the validity of HR$V \mathrm{O}_{2}$, whereas in handball (Buchheit et al., 2009) and in this study with futsal, $\mathrm{HR}-\mathrm{VO}_{2}$ was not valid for the estimation of $V \mathrm{O}_{2}$ by $\mathrm{HR}$ from the continuous progressive test. Another interesting fact in this study is that the comparison between Measured- $V \mathrm{O}_{2}$ and Estimated- $V \mathrm{O}_{2}$ from $\mathrm{HR}-V \mathrm{O}_{2}$ was made by calculating the integral area of $\mathrm{VO}_{2}$ over the time during $\mathrm{S}$-Game since for each recorded $\mathrm{HR}$ there are different $V \mathrm{O}_{2}$ values. In other studies, $\mathrm{VO}_{2}$ was estimated using the $\mathrm{HR}_{\text {mean }}$ of the exercise (Esposito et al., 2004; Castagna et al., 2007; Makaje et al., 2012), which can be a bias of those studies.

In addition to $\mathrm{HR}-\mathrm{VO}_{2}$ and the aerobic $\mathrm{EE}$, we also calculated the total EE (i.e., $\left.W_{\mathrm{AER}}+W_{\mathrm{PCR}}+W_{\left[\mathrm{La}^{-}\right]}\right)$. The same method for calculating the total $\mathrm{EE}$ has been used in other sports, as tae kwon do (Campos et al., 2012), climbing (Bertuzzi et al., 2007), rowing (de Campos Mello et al., 2009), and table tennis (Zagatto et al., 2016). In all these studies about EE and as also verified in this study, the calculated value of the lactic anaerobic pathway has been the lowest value, which can be a characteristic of the sports evaluated or a limitation of the method. Certainly, the measurement of anaerobic EE is more difficult than aerobic EE, and it has limitations. For example, in an incremental exercise, it is recommended that stages between 3 and $6 \mathrm{~min}$ be used to obtain precise $\left[\mathrm{La}^{-}\right]$measurements (Bentley et al., 2007), ensuring the efflux of muscle lactate to not underestimate the $\left[\mathrm{La}^{-}\right]$value. In contrast, if after 5-6 min the lactate efflux from the muscle into the blood is guaranteed, the measurement taken in a time above this can lead to loss of information. Completing this idea, Stølen et al. (2005) pointed out that, in soccer, the $\left[\mathrm{La}^{-}\right]$measure depends largely on the activity pattern in 5 min preceding the sample collection, since $\left[\mathrm{La}^{-}\right]$results from the production/removal ratio, which is influenced by the value of the lactate produced, activity during the recovery period, and aerobic capacity. In addition, for the 5 vs. 5 small-sided games in soccer, Hoff et al. (2002) indicated 
$4 \mathrm{~min}$ of play to reach at least $3 \mathrm{~min}$ at high intensity. Thus, we suggested that in future studies, mainly on futsal, blood samples be taken with $V_{2}$ at 3, 4, and/or $5 \mathrm{~min}$ to verify if the length of the playing period can influence the calculation of the lactic EE per minute, since the intensity of the futsal game is higher than in soccer and $\mathrm{HR}$ average is $90 \% \mathrm{HR}_{\max }$ (Barbero-Alvarez et al., 2008), with less variation in HR (i.e., coefficient of variation $=7 \%$ ) during the game (Dos-Santos et al., 2020).

The alactic EE also has limitations and can be underestimated due to the intermittent character of the futsal game with changes between high-intensity activity and the activities of lower intensity and pauses, which reduce the $\mathrm{VO}_{2}$. However, the $V \mathrm{O}_{2}$ recovery of those $V \mathrm{O}_{2}$ reduction periods is not considered or measured during the game, limiting the exact calculation of the $W_{\text {PCR }}$.

The EE in the S-Game was determined, disregarding the resting $\mathrm{VO}_{2}$, to account only the activity EE of futsal. The total EE measured was $13.10 \pm 1.25 \mathrm{kcal} . \mathrm{min}^{-1}, W_{\mathrm{AER}}=93 \%, W_{\mathrm{PCR}}$ $=5 \%$, and $W_{\left[\mathrm{La}^{-}\right]}=2 \%$. The aerobic EE measured was $12.19 \pm$ $1.09 \mathrm{kcal} . \mathrm{min}^{-1}$. In futsal game with recreational players, Beato et al. (2016) found $634 \pm 92 \mathrm{kcal}$ for $52 \pm 2 \mathrm{~min},(\approx 12.19$ kcal.min $\left.{ }^{-1}\right)$, and Makaje et al. (2012) found $595 \pm 50 \mathrm{kcal}$ $\left(\approx 14.81 \mathrm{kcal} . \mathrm{min}^{-1}\right)$ for elite players and $543 \pm 67 \mathrm{kcal}(\approx 13.57$ kcal.min ${ }^{-1}$ ) for amateurs. Both studies were estimated by HR$V \mathrm{O}_{2}$ relation, and they were close to the values evidenced in this study. However, in official games, Rodrigues et al. (2011) found higher values than the ones in the present study and the other studies, $18 \mathrm{kcal} . \mathrm{min}^{-1}$. In this case, the $\mathrm{EE}$ is expected to be higher in official games, or the value might have been overestimated, reinforcing that caution is needed in estimating $\mathrm{EE}$ from $\mathrm{HR}-\mathrm{VO}_{2}$.

Considering the EE expressed in METs, the total EE of SGame was 10.81 METs, which is a higher EE than in other team sports such as soccer (10.0 METs) and basketball (7.0 METs) (Ainsworth et al., 2000). The results expressed in METs of the EE of S-Game reinforce the findings of Barbero-Alvarez et al. (2008), which show that futsal is more intense than soccer, basketball, and handball. Our results can serve as a reference to guide and assist in assessment and prescription programs for weight control and exercise for health.

Although there is a limitation in the determination of the alactic and lactic anaerobic in intermittent exercise, it was possible to add information and to obtain the EE closest to the real one. This is the first study that proposed to investigate the anaerobic EE response and to add information about total $\mathrm{EE}$ in futsal. Further studies on total EE in futsal shorter-duration games are needed so that the anaerobic pathways are not thus underestimated. The shorterduration games supposedly demand greater stress, intensity, heat production, intermittency, and alteration of game activities, i.e., the variables that may interfere with the physiological responses of the players.

\section{CONCLUSION}

The $\mathrm{HR}-V \mathrm{O}_{2}$ from the continuous test did not accurately estimate $V \mathrm{O}_{2}$ in the futsal game. HR- $V \mathrm{O}_{2}$ is not recommended for estimating $\mathrm{VO}_{2}$ and calculating individual $\mathrm{EE}$ in futsal, since it does not present acceptable agreement and correlation with the Measured- $V \mathrm{O}_{2}$ in the futsal game. The values estimated by $\mathrm{HR}-V \mathrm{O}_{2}$ approach the average value of the game, which can only be used to estimate the "rough" $V \mathrm{O}_{2}$ of groups. The SGame presented the total EE (i.e., $\left.W_{\mathrm{AER}}+W_{\mathrm{PCR}}+W_{\left[\mathrm{La}^{-}\right]}\right)$of $13.10 \pm 1.25 \mathrm{kcal} . \mathrm{min}^{-1}$. In futsal (S-Game), the highest demand came from the aerobic pathway, $93 \%$, from the alactic anaerobic pathway, $5 \%$, and from the lactic anaerobic pathway, $2 \%$.

\section{DATA AVAILABILITY STATEMENT}

The original contributions and raw data presented in the study are included in the article, further inquiries can be directed to the corresponding author.

\section{ETHICS STATEMENT}

The studies involving human participants were reviewed and approved by Ethics Committee of School of Science, São Paulo State University (UNESP), Bauru, Brazil, in accordance with local laws and ethical standards established in the Declaration of Helsinki. The patients/participants provided their written informed consent to participate in this study.

\section{AUTHOR CONTRIBUTIONS}

HS and JD-S planed the study. HS contributed to the data collection, statistical analysis, and manuscript writing. AS contributed to the analysis and design. FN and MP have made substantial contributions to conception and design. JD-S, HS, and FN reviewed the manuscript, and JD-S contributed to conception and approval of the final version for publication. All authors have approved the final version of the manuscript.

\section{FUNDING}

This study was financially supported by the National Council for Scientific and Technological Development (CNPq, Process: 160137/2014-4) and was also carried out with the support of the Coordination for the Improvement of Higher Education Personnel (CAPES), Brazil (Finance Code 001).

\section{ACKNOWLEDGMENTS}

The authors thank the staff of the Department of Physical Education of UNESP, Bauru, the technical committee and players of AA FIB Futsal, and the members of the research group FITES for their support. 


\section{REFERENCES}

Achten, J., and Jeukendrup, A. E. (2003). Heart rate monitoring: applications and limitations. Sport. Med. 33, 517-538. doi: 10.2165/00007256-200333070-00004

Ainsworth, B. E., Haskell, W. L., Whitt, M. C., Irwin, M. L., Swartz, A. M., Strath, S. J., et al. (2000). Compendium of physical activities: an update of activity codes and MET intensities. Med. Sci. Sports Exerc. 32, S498-S504. doi: 10.1097/00005768-200009001-00009

Balsom, P. D., Seger, J. Y., Sjodin, B., and Ekblom, B. (1992). Maximal-intensity intermittent exercise: effect of recovery duration. Int. J. Sports Med. 13, 528-533. doi: 10.1055/s-2007-1021311

Bangsbo, J., Mohr, M., and Krustrup, P. (2006). Physical and metabolic demands of training and match-play in the elite football player. J. Sports Sci. 24, 665-674. doi: 10.1080/02640410500482529

Barbero-Alvarez, J. C., Soto, V. M., Barbero-Alvarez, V., and Granda-Vera, J. (2008). Match analysis and heart rate of futsal players during competition. J. Sports Sci. 26, 63-73. doi: 10.1080/02640410701287289

Beato, M., Impellizzeri, F. M., Coratella, G., and Schena, F. (2016). Quantification of energy expenditure of recreational football. J. Sports Sci. 34, 2185-2188. doi: 10.1080/02640414.2016.1167280

Beneke, R., Pollmann, C., Bleif, I., Leithäuser, R. M., and Hütler, H. (2002). How anaerobic is the wingate anaerobic test for humans? Eur. J. Appl. Physiol. 87, 388-392. doi: 10.1007/s00421-002-0622-4

Bentley, D. J., Newell, J., and Bishop, D. (2007). Incremental exercise test design and analysis: implications for performance diagnostics in endurance athletes. Sport. Med. 37, 575-586. doi: 10.2165/00007256-200737070-00002

Bertuzzi, R. C., de, M., Franchini, E., Kokubun, E., and Kiss, M. A. P. D. M. (2007). Energy system contributions in indoor rock climbing. Eur. J. Appl. Physiol. 101, 293-300. doi: 10.1007/s00421-007-0501-0

Bertuzzi, R. C. M., Franchini, E., Ugrinowitsch, C., Kokubun, E., Lima-Silva, A. E., Pires, F. O., et al. (2010). Predicting MAOD using only a supramaximal exhaustive test. Int. J. Sports Med. 31, 477-481. doi: 10.1055/s-0030-1253375

Buchheit, M., Lepretre, P. M., Behaegel, A. L., Millet, G. P., Cuvelier, G., and Ahmaidi, S. (2009). Cardiorespiratory responses during running and sport-specific exercises in handball players. J. Sci. Med. Sport 12, 399-405. doi: 10.1016/j.jsams.2007.11.007

Campos, F. A. D., Bertuzzi, R., Dourado, A. C., Santos, V. G. F., and Franchini, E. (2012). Energy demands in taekwondo athletes during combat simulation. Eur. J. Appl. Physiol. 112, 1221-1228. doi: 10.1007/s00421-011-2071-4

Castagna, C., Belardinelli, R., Impellizzeri, F. M., Abt, G. A., Coutts, A. J., and D'Ottavio, S. (2007). Cardiovascular responses during recreational 5-a-side indoor-soccer. J. Sci. Med. Sport 10, 89-95. doi: 10.1016/j.jsams.2006.05.010

Castagna, C., D’Ottavio, S., Vera, J. G., and Álvarez, J. C. B. (2009). Match demands of professional Futsal: a case study. J. Sci. Med. Sport 12, 490-494. doi: 10.1016/.j.jsams.2008.02.001

Cohen, J. (1988). Statistical Power Analysis for the Behavioural Sciences. Hillside, NJ: Lawrence Earlbaum Assoc.

de Campos Mello, F., de Moraes Bertuzzi, R. C., Grangeiro, P. M., and Franchini, E. (2009). Energy systems contributions in 2,000 m race simulation: a comparison among rowing ergometers and water. Eur. J. Appl. Physiol. 107, 615-619. doi: 10.1007/s00421-009-1172-9

Di Prampero, P. E., and Ferretti, G. (1999). The energetics of anaerobic muscle metabolism: a reappraisal of older and recent concepts. Respir. Physiol. 118, 103-115. doi: 10.1016/S0034-5687(99)00083-3

Dos-Santos, J. W., da Silva, H. S., da Silva Junior, O. T., Barbieri, R. A., Penafiel, M. L., da Silva, R. N. B., et al. (2020). Physiology responses and players' stay on the court during a futsal match: a case study with professional players. Front. Psychol. 11:620108. doi: 10.3389/fpsyg.2020.620108

Esposito, F., Impellizzeri, F. M., Margonato, V., Vanni, R., Pizzini, G., and Veicsteinas, A. (2004). Validity of heart rate as an indicator of aerobic demand during soccer activities in amateur soccer players. Eur. J. Appl. Physiol. 93, 167-172. doi: 10.1007/s00421-004-1192-4

Glickman, L. V., and Rowntree, D. (1982). Statistics Without Tears, a Primer for Non-Mathematicians. Harmondsworth: Penguin.

Hoff, J., Wisløff, U., Engen, L. C., Kemi, O. J., and Helgerud, J. (2002). Soccer specific aerobic endurance training. Br. J. Sports Med. 36, 218-221. doi: $10.1136 /$ bjsm.36.3.218

Howley, E. T., Bassett, D. R., and Welch, H. G. (1995). Criteria for maximal oxygen uptake: review and commentary. Med. Sci. Sports Exerc. 27, 1292-1301. doi: 10.1249/00005768-199509000-00009

Kuipers, H., Rietjens, G., Verstappen, F., Schoenmakers, H., and Hofman, G. (2003). Effects of stage duration in incremental running tests on physiological variables. Int. J. Sports Med. 24, 486-491. doi: 10.1055/s-2003-42020

Lin, L. I.-K. (1989). A concordance correlation coefficient to evaluate reproducibility. Biometrics 45:255. doi: 10.2307/2532051

Makaje, N., Ruangthai, R., Arkarapanthu, A., and Yoopat, P. (2012). Physiological demands and activity profiles during futsal match play according to competitive level. J. Sport. Med Phys. Fit. 52, 366-374.

Margaria, R., Edwards, H. T., and Dill, D. B. (1933). The possible mechanisms of contracting and paying the oxygen debt and the rôle of lactic acid in muscular contraction. Am. J. Physiol. Content 106, 689-715. doi: 10.1152/ajplegacy.1933.106.3.689

McArdle, W., Katch, F., and Katch, V. (2014). Exercise Physiology: Nutrition, Energy, and Human Performance (International Edition), 7th Edn. Philadelphia, PA, London: Wolters Kluwer/Lippincott Williams and Wilkins.

Milioni, F., Vieira, L. H., Barbieri, R. A., Zagatto, A. M., Nordsborg, N. B., Barbieri, F. A., et al. (2016). Futsal match-related fatigue affects running performance and neuromuscular parameters but not finishing kick speed or accuracy. Front. Physiol. 7:518. doi: 10.3389/fphys.2016.00518

Özyener, F., Rossiter, H. B., Ward, S. A., and Whipp, B. J. (2001). Influence of exercise intensity on the on- and off- transient kinetics of pulmonary oxygen uptake in humans. J. Physiol. 533, 891-902. doi: 10.1111/j.1469-7793.2001.t01-1-00891.x

Rodrigues, V. M., Ramos, G. P., Mendes, T. T., Cabido, C. E. T., Melo, E. S., Condessa, L. A., et al. (2011). Intensity of official futsal matches. J. Strength Cond. Res. 25, 2482-2487. doi: 10.1519/JSC.0b013e3181fb4574

Stølen, T., Chamari, K., Castagna, C., and Wisløff, U. (2005). Physiology of soccer: an update. Sport. Med. 35, 501-536. doi: 10.2165/00007256-200535060-00004

Zagatto, A. M., De Mello Leite, J. V., Papoti, M., and Beneke, R. (2016). Energetics of table tennis and table tennis-specific exercise testing. Int. J. Sports Physiol. Perform. 11, 1012-1017. doi: 10.1123/ijspp.2015-0746

Conflict of Interest: The authors declare that the research was conducted in the absence of any commercial or financial relationships that could be construed as a potential conflict of interest.

Publisher's Note: All claims expressed in this article are solely those of the authors and do not necessarily represent those of their affiliated organizations, or those of the publisher, the editors and the reviewers. Any product that may be evaluated in this article, or claim that may be made by its manufacturer, is not guaranteed or endorsed by the publisher.

Copyright (๑ 2021 Silva, Nakamura, Papoti, da Silva and Dos-Santos. This is an open-access article distributed under the terms of the Creative Commons Attribution License (CC BY). The use, distribution or reproduction in other forums is permitted, provided the original author(s) and the copyright owner(s) are credited and that the original publication in this journal is cited, in accordance with accepted academic practice. No use, distribution or reproduction is permitted which does not comply with these terms. 